\title{
DO DANO MORAL DECORRENTE DA DIFUSÃO VOLUNTÁRIA DE DADOS PESSOAIS NÃO CONSENTIDA PELO TITULAR
}

\section{Catiane Medianeira Milanii'; Otávio Augusto Milani Nunes ${ }^{2}$; Mariana Moreira Moura ${ }^{3 ;}$ João Pedro Seefeldt Pessoa ${ }^{4}$}

\section{RESUMO}

A interpretação dos institutos jurídicos deve acompanhar a realidade social a fim de conformá-los com as situações fáticas da sociedade moderna inevitavelmente conectada. A nova fase normativa inaugurada pela Lei Geral de Proteção de Dados tem o potencial de moldar comportamentos dos atores sociais de forma a preservar e proteger os direitos constitucionais fundamentais da sociedade da informação. Novos conceitos devem ser construídos e antigas definições devem ser reinterpretadas. Assim, utilizando o método dialético em conjunto com o monográfico, apoiados em pesquisa indireta documental e bibliográfica e partindo do entendimento adotado no julgamento do recurso cível no 71009738089, este artigo buscará demonstrar que o direito fundamental à proteção de dados pessoais, quando violado por conduta voluntária do agente de tratamento, poderá caracterizar dano moral in re ipsa. O resultado alcançado é que há condutas de tratamento de dados pessoais que, principalmente por sua gravidade, implicam dano moral presumido.

Palavras-chave: Indenização; LGPD; Privacidade; Tratamento.

Eixo Temático: Direitos, Políticas Públicas e Diversidade - DPD.

\section{INTRODUÇÃO}

Na sociedade contemporânea, hiper conectada e hiper vigiada, o fluxo e o compartilhamento de dados é contínuo e inevitável, notadamente de dados pessoais, sendo seu fornecimento indispensável na era da Indústria 4.0, chegando a fazer às

\footnotetext{
${ }^{1}$ Autora: Procuradora Federal, Pós-graduanda em Advocacia Pública na Escola da Advocacia-Geral da União; E-mail: catianemilani@gmail.com

2 Autor. Acadêmico de Direito na Universidade Federal de Santa Maria; E-mail: otavioamnunes@gmail.com

3 Autora: Acadêmica de Direito na Universidade Federal de Santa Maria; E-mail: marimoreiramoura@gmail.com

${ }^{4}$ Orientador. Professor no Departamento de Direito da Universidade Federal de Santa Maria. Mestre em Direito pela Universidad de León (ULE) e Mestre em Direito pela Universidade Federal de Santa Maria - UFSM E-mail: joao.seefeldt@ufsm.br
} 
vezes da própria pessoa em uma série de circunstâncias nas quais a presença física outrora seria indispensável (DONEDA, 2011). Em decorrência dessa nova realidade inevitavelmente cada vez mais digital, multiplicam-se as controvérsias judiciais envolvendo a personalidade do indivíduo independentemente de eventual repercussão patrimonial, destacando-se as pretensões indenizatórias sobre os direitos da personalidade, em especial sobre o tratamento de dados pessoais.

Partindo-se da premissa de que a proteção de dados pessoais, em tempos em que impera o capitalismo de vigilância, é reconhecida como direito fundamental, temse como consequência que sua violação impõe ao responsável o dever de indenizar o dano material ou moral decorrente da violação.

Nesse cenário, a Lei no 13.709 de 14 de agosto de 2018 (BRASIL, 2018), conhecida como Lei Geral de Proteção de Dados Pessoais - LGPD, inaugurou no Brasil uma nova fase normativa na proteção dos dados pessoais. Com o objetivo de proteger os direitos fundamentais de liberdade $e$ de privacidade e o livre desenvolvimento da personalidade da pessoa natural, a LGPD reforça, principalmente em seu art. 42, a responsabilidade civil daquele que, ao tratar dados pessoais, causar a outrem dano patrimonial, moral, individual ou coletivo.

Diante desse novo horizonte, como problema de pesquisa, questiona-se: a publicização de dados pessoais, não consentida pelo titular, decorrente de conduta voluntária do agente de tratamento, isto é, não decorrente de intervenção externa, caracteriza dano moral indenizável in re ipsa, sendo presumido o dano; ou, se além da prova da efetiva ocorrência do ato danoso e do nexo de causalidade é necessário provar, também, o dano concreto suportado pelo ofendido.

Para balizar a presente análise, parte-se do entendimento fixado pela Primeira Turma Recursal da Fazenda Pública dos Juizados Especiais Cíveis do Estado do Rio Grande do Sul, por ocasião do julgamento do Recurso Cível, no 71009738089 (RIO GRANDE DO SUL, 2021), que sinaliza em sentido contrário ao que despontaria como majoritário na doutrina e jurisprudência em formação.

O estudo justifica-se essencialmente na necessidade de conscientização dos agentes de tratamento e também dos titulares de dados pessoais acerca da necessidade de maximizar a contínua implementação e observância de medidas 
EDUCAÇÃO, SAÚDE

ETECNOLOGIA

26 A 28 DE OUTUBRO DE 2021

técnicas aptas a proteger os dados pessoais, prevenindo a ocorrência de danos reais ou potenciais, próximos ou futuros, e restringindo o tratamento ao mínimo necessário para a realização de suas finalidades, diretivas consagradas na base principiológica da LGPD assim como por outros regramentos de segurança de dados pessoais, inclusive no Regulamento Geral sobre Proteção de Dados da União Europeia - RGPD.

A difusão irresponsável de dados pessoais, em desacordo com a LGPD e por conduta voluntária do agente de tratamento, por constituir espécie nuclear mais gravosa, não deve ser tolerada nem ter suas consequências minimizadas, sob pena de destruir a eficácia da proteção de dados pessoais pretendida pelo legislador, em obediência às novas conformações dos direitos fundamentais de liberdade e privacidade da atual sociedade da informação incessantemente conectada em rede.

\section{METODOLOGIA}

Em termos metodológicos, é utilizado o método de abordagem dialético, a fim de analisar, qualitativamente, o objeto de pesquisa, realizando uma conexão relacional e recíproca entre os temas tratados, especialmente o estudo de caso para com os regramentos relativos. Quanto ao procedimento, utiliza-se o método monográfico, com a intenção de obter conclusões sobre o tema a partir da análise relacional de um precedente judicial. Em relação às técnicas de pesquisa, faz-se uso da documentação indireta, com pesquisa documental e bibliográfica.

\section{RESULTADOS E DISCUSSÃO}

O debate proposto no presente trabalho tem por objetivo investigar os dois principais entendimentos que retratam a provável divergência que será objeto de controvérsia nas demandas judiciais envolvendo responsabilidade civil pelo tratamento de dados, notadamente pretensões indenizatórias decorrentes da difusão de dados pessoais, sem a autorização do titular, por conduta voluntária do agente de tratamento. Em síntese, será analisado se para a caracterização de dano moral indenizável é suficiente a mera comprovação do ato ilícito e do nexo de causalidade ou se é necessário comprovar, também, a ocorrência de dano decorrente da divulgação de dados pessoais em desacordo com a LGPD. 


\subsection{DO DANO MORAL}

A Constituição Federal (BRASIL, 1988), no art. 5ำ, sobre direitos e garantias fundamentais, refere que todos são iguais perante a lei, sem distinção de qualquer natureza, garantindo-se aos brasileiros e aos estrangeiros residentes no País a inviolabilidade do direito à vida, à liberdade, à igualdade, à segurança e à propriedade. Estabelece, também, no art. 5ำ inc. V, que é assegurado o direito de resposta, proporcional ao agravo, além da indenização por dano material, moral ou à imagem.

O Código Civil (BRASIL, 2002), no art. 186, menciona que aquele que, por ação ou omissão voluntária, negligência ou imprudência, violar direito e causar dano a outrem, ainda que exclusivamente moral, comete ato ilícito, sendo que, no art. 187, continua dizendo que também comete ato ilícito o titular de um direito que, ao exercêlo, excede manifestamente os limites impostos pelo seu fim econômico ou social, pela boa-fé ou pelos bons costumes. No que tange à obrigação de indenizar, o Código Civil, no art. 927, enuncia que aquele que, por ato ilícito (arts. 186 e 187), causar dano a outrem, fica obrigado a repará-lo.

Apesar do dissenso que acompanhou a definição de dano moral e a possibilidade de sua aplicação, cujo ressarcimento era praticamente inexequível até a Constituição Federal de 1988, notadamente se não decorresse de um dano material (STIEFELMANN, 2007), atualmente há consenso sobre a possibilidade de seu ressarcimento mesmo que desacompanhado de dano material.

O dissenso permanece, contudo, sobre as hipóteses que caracterizam dano moral, já tendo a doutrina e jurisprudência construído há algum tempo diretrizes sobre sua caracterização, em especial sobre a necessidade de a situação extrapolar atos do cotidiano da vida em sociedade, produzindo consequências que ultrapassem o que se entende por mero aborrecimento ou dissabor inerentes à normalidade do dia a dia.

Há conformidade, também, quanto aos pressupostos para sua comprovação, quais sejam, conduta - omissiva ou comissivo - que caracterize dano e nexo de causalidade entre esses dois elementos. Seja de caráter punitivo, reparatório ou educativo, multifuncionalidade da responsabilidade civil ainda objeto de acirrados debates na doutrina e jurisprudência brasileira, incontroverso que uma vez 
comprovados os referidos pressupostos, surge ao ofendido o direito de buscar a reparação do dano sofrido, "desfazendo tanto quanto possível seus efeitos, restituindo o prejudicado ao status quo ante" (DINIZ, 2003).

No que tange ao dano, a depender do bem da vida atingido, ele pode ser patrimonial (material) ou extrapatrimonial (moral). Dentre as modalidades de dano moral, nos interessa o dano moral in re ipsa, que se configura com a mera ocorrência da situação fática, sendo desnecessário provar a efetiva ocorrência do dano. O dano, nesse caso, é presumido, como ocorre, por exemplo, com a publicação não autorizada de imagem da pessoa com fins econômicos ou comerciais (BRASIL, STJ, Súmula 403), com a inscrição ou manutenção indevida de nome em cadastros de proteção ao crédito e no caso de morte de ente familiar.

Inobstante eventuais divergências sobre o enquadramento de condutas fáticas como passíveis de caracterizar dano moral presumido, fato é que a ocorrência de algumas situações traz, por si só, o potencial de, pela mera ocorrência no mundo fático, lesionar direito protegido pela ordem jurídica, dispensando a prova da efetiva ocorrência do dano concreto. Assim, questiona-se se a difusão de dados pessoais, sem consentimento do titular e por conduta voluntária do agente de tratamento, teria o potencial de caracterizar dano moral in re ipsa?

\subsection{DO TRATAMENTO E DA PROTEÇÃO DE DADOS PESSOAIS}

A evolução na proteção de dados pessoais, que para alguns doutrinadores pode ser classificada em quatro diferentes gerações de leis (MAYER-SCÖNBERGER, 1997), inicia com uma abordagem técnica e restrita, evoluindo para acompanhar a massiva inclusão digital no ciberespaço com a "datificação das coisas". A proteção, que era individual, técnica e restrita, passa a ser coletiva, ampla e preventiva (PESSOA, 2020).

No Brasil, o direito à privacidade e à intimidade, assim como à inviolabilidade da comunicação de dados, constituem garantia fundamental (art. 5ำ X e XII, CF), razão pela qual, conforme recentemente decidiu o Supremo Tribunal Federal -STF (BRASIL, 2021), por ocasião do julgamento da Ação Direta de Inconstitucionalidade no 6.387, o tratamento e a manipulação de dados pessoais, na medida em que 
relacionados à identificação efetiva ou potencial da pessoa natural, devem observar os limites delineados pelo âmbito de proteção das cláusulas constitucionais, sob pena caracterizar lesão a esses direitos.

Após menção ao caráter de direito fundamental da proteção de dados pessoais no ambiente normativo interno, em 15 de novembro de 2003, quando o Governo Brasileiro firmou a Declaração de Santa Cruz de La Sierra, que em seu item 45 dispunha que os signatários estavam conscientes de que "a proteção de dados pessoais é um direito fundamental das pessoas [...], os debates sobre a matéria culminaram com a edição da Lei no 13.709 de 14 de agosto de 2018, conhecida como Lei Geral de Proteção de Dados Pessoais (LGPD), que positivou como fundamentos específicos da proteção de dados pessoais o respeito à privacidade, à liberdade e à autodeterminação informativa, complementando a proteção já conferida principalmente pelo Código de Defesa do Consumidor e pelo Marco Civil da Internet.

Os dados pessoais, conforme reconhece o Núcleo de Proteção de Dados do Conselho Nacional de Defesa do Consumidor, são a representação do indivíduo na sociedade e, por isso, são parte de sua personalidade, foram definidos pela LGPD, em seu art. 5, I, como qualquer "informação relacionada a pessoa natural identificada ou identificável". A LGPD conceitua, também, no inciso X do mesmo artigo, o tratamento de dados de modo a compreender qualquer operação realizada com dados pessoais, como as que se referem a reproduzir, coletar, transmitir, distribuir, processar, modificar, transferir, difundir ou extrair.

Destarte, qualquer operação envolvendo informação relacionada à identificação - efetiva ou potencial - de pessoa natural realizada por agente de tratamento, isto é, qualquer pessoa natural ou pessoa jurídica de direito público ou direito privado, deve observar as normas da LGPD, assim entendidas as regras e princípios que orientam referida lei, sendo assegurado ao titular do dado, dentre outros direitos, a possibilidade de acompanhar e controlar o tratamento.

Em consequência, se houver divulgação de dados pessoais, por agente de tratamento, em desacordo com a LGPD, em tese, estará caracterizada a violação à proteção de dados, implicando, por conseguinte, lesão ao direito do titular dos dados, que teve suas informações pessoais divulgadas sem sua autorização. 


\subsection{DO RECURSO CÍVEL № 71009738089}

Apesar da atualidade do normativo legal, a aplicação de suas previsões já bateu às portas do Poder Judiciário, embasando ações que englobam pretensões diversas, notadamente indenizatórias. Em oportunidade anterior, o Tribunal de Justiça do Rio Grande do Sul - TJRS, acompanhando entendimento que vem sendo albergado pelo Tribunal de Justiça de São Paulo - TJSP, entendeu que a ausência de comprovação da efetiva ocorrência de abalo em algum dos atributos da personalidade afastaria a pretensão indenizatória.

Entretanto, adotando postura inovadora, em recente precedente datado de 24/08/2021, os Juízes de Direito integrantes da Primeira Turma Recursal da Fazenda Pública dos Juizados Especiais Cíveis do Estado do Rio Grande do Sul, à unanimidade, negaram provimento ao Recurso Inominado № 71009738089, mantendo sentença que entendeu pela possibilidade de reconhecimento de dano moral puro, ou seja, "in re ipsa, uma vez que foi atingido direito personalíssimo da parte autora, notadamente, a privacidade de seus dados pessoais".

$\mathrm{Na}$ situação concreta que deu origem ao referido processo, o pedido de reparação do dano moral teve por base a violação do sigilo dos dados pessoais da parte autora, que, ao participar de um concurso público municipal, teve os números de seu RG e CPF divulgados, em páginas da internet, através de sítio eletrônico, mediante publicação de edital, informado o local de realização das provas do certame, constando, ao lado de seu nome, os referidos dados pessoais.

As alegações defensivas embasadas na publicidade dos atos da Administração Pública e na ausência de prejuízo foram rejeitadas, entendendo a sentença, mantida à unanimidade em sede recursal por decisão ainda não transitada em julgado, pela caracterização de dano moral independente da prova da efetiva ocorrência do dano, pois

[...] com a divulgação de tais informações, a parte autora fica vulnerável a prática criminosas, como fraudes e estelionatos realizados por terceiros com a utilização de seus números de CPF e RG. Isso se torna ainda mais grave em virtude de a divulgação ter ocorrido pela internet, de modo que criminosos do mundo todo podem ter acesso aos dados pessoais da autora. Logo, 
desnecessária prova específica de que eventual delito assim tenha ocorrido, pois a mera divulgação dos dados pessoais fragiliza a privacidade e segurança do autor, expondo a riscos (Recurso Cível, № 71009738089, Turma Recursal da Fazenda Pública, Turmas Recursais, Relator: Maria Beatriz Londero Madeira, Julgado em: 24-08-2021).

A corroborar a conclusão de que o sentimento de insegurança experimentado pelo titular dos dados pessoais, que sem a sua autorização tem suas informações disponibilizadas em bancos de dados de fácil acesso por terceiros caracteriza dano moral puro, há recente acórdão unânime do Superior Tribunal de Justiça - STJ, no julgamento do recurso especial n 1.758.799/MG, que entendeu não merecer reparos os fundamentos de decisão reconhecendo a ocorrência de dano moral in re ipsa na conduta "[...] no mínimo inconsequente na medida em que facilita o acesso aos dados pessoais da pessoa cadastrada, sem o seu consentimento expresso, o que favorece a prática de atos ilícitos ou contratações fraudulentas por terceiros de má-fé" .

No que tange ao regime da responsabilidade civil, o art. 42 da LGPD é palco de entendimentos divergentes, alguns defendendo a responsabilidade subjetiva, outros a responsabilidade objetiva. Inobstante, independentemente do regime de responsabilidade civil, o fato de o agente de tratamento supostamente violador da legislação pertinente à proteção de dados pessoais pertencer à Administração Pública não afasta a presunção do dano moral, mas, pelo contrário, confirma a incidência, especialmente considerando a responsabilidade objetiva prevista no $\S 6^{\circ}$, do art. 37 , da Constituição Federal.

Depreende-se, assim, que no regime normativo instituído pela LGPD, considerado um marco regulatório da segurança no ciberespaço, no que tange ao dano, há condutas que caracterizam tratamentos de dados pessoais, dentre eles a publicização, em desacordo com a LGPD, que podem - e devem - implicar, por si só, dano moral indenizável in re ipsa, principalmente em razão da gravidade da conduta danosa e dos reflexos reais ou potenciais na vida do ofendido. Exigir comprovação da efetiva ocorrência de dano nesses casos representaria impor ao ofendido ônus probatório excessivo, incentivando comportamentos irresponsáveis por parte dos agentes de tratamentos de dados e minimizando o evento danoso. 
Afinal, o "novo petróleo" da sociedade e economia baseada em dados - há quem afirme inclusive que os dados seriam até mais valiosos - deve ser protegido por posturas proativas visando potencializar a eficácia das previsões normativas que tutelam as novas conformações dos direitos fundamentais de liberdade e privacidade da atual sociedade da informação conectada em rede.

\section{CONCLUSÃO}

Nos casos de tratamento de dados pessoais em desconformidade com a Lei Geral de Proteção de Dados Pessoais (LGPD), especialmente de difusão de informações sem o consentimento do titular, os danos daí advindos são in re ipsa, tendo em vista que o evento danoso reside no próprio fato, ou seja, verifica-se na própria ocorrência do ato antijurídico, sendo presumido o abalo moral ao titular dos dados pessoais. O precedente $\mathrm{n}^{\circ}$ 71009738089, da Primeira Turma Recursal da Fazenda Pública dos Juizados Especiais Cíveis do Estado do Rio Grande do Sul, caminha em importante sentido acompanhando a evolução da sociedade, quando reconhece que a publicização de dados pessoais por conduta voluntária do agente de tratamento e sem o consentimento do titular implica lesão presumida indenizável hábil a atingir a privacidade, liberdade, igualdade e segurança do indivíduo, direitos que hoje devem ser considerados sob um prisma mais abrangente que o sentido clássico, que se revelam insuficientes para assegurar uma regulação adequada e eficaz.

A (re)construção de uma cultura de privacidade, cuja manifestação mais tradicional compreendia o "direito de estar só", assim como a (re)interpretação da responsabilidade civil, classicamente compreendida como reparação do dano, exigem, principalmente nessa fase inicial de vigência da nova legislação e modulagem de comportamentos a partir da inovação legislativa, uma postura proativa dos atores sociais a fim de evitar a banalização de atos irrefletidos por parte dos agentes de tratamento e inibir ocorrências de novas e similares condutas que possam desvirtuar a eficácia da proteção inaugurada pela LGPD.

Neste contexto, em uma sociedade datificada já composta por nativos digitais, a violação do direito constitucional à proteção de dados pessoais desafia o sistema jurídico tradicional, exigindo revisão de paradigmas, entendendo-se caracterizado o 
EDUCAÇÃO, SAÚDE

ETECNOLOGIA

26 A 28 DE OUTUBRO DE 2021

dano in re ipsa em caso de tratamento de dados em desacordo com a LGPD, haja vista que algumas condutas de tratamento de dados pessoais operadas de forma ilegal, ilegítima, irregular, inadequada, desnecessária, dentre outras hipóteses, são suficientes para privar o indivíduo do pleno gozo dos direitos da personalidade. $O$ fato de o agente de tratamento supostamente violador da legislação pertinente à proteção de dados pessoais pertencer à Administração Pública não afasta a presunção do dano moral, mas, pelo contrário, evidencia a incidência, especialmente considerando a responsabilidade objetiva.

\section{REFERÊNCIAS}

BRASIL. Constituição da República Federativa do Brasil de 1988. Disponível em: http://www.planalto.gov.br/ccivil 03/constituicao/constituicao.htm. Acesso em 18 set. 2021.

Lei oㅡ 8.078 de 11 de setembro de 1990. Dispõe sobre a proteção do consumidor e dá outras

providências.

Disponível

em:

http://www.planalto.gov.br/ccivil 03/leis//8078compilado.htm. Acesso em: 18 set. 2021

Lei oㅜ 10.406, de 10 de janeiro de 2002. Institui o Código Civil.

Disponível em: http://www.planalto.gov.br/ccivil 03/leis/2002/L10406compilada.htm. Acesso em: 18 set.2021.

Lei oㅜ 12.965 de 23 de abril de 2014. Estabelece princípios, garantias,

direitos e deveres para o uso da Internet no Brasil. Disponível em: http://www.planalto.gov.br/ccivil 03/ ato2011-2014/2014/lei//12965.htm. Acesso em: 18 set. 2021. 


\section{QUFN}

Lei ํo 13.709, de 14 de agosto de 2018. Lei Geral de Proteção de

Dados

Pessoais

(LGPD).

Disponível

em:

http://www.planalto.gov.br/ccivil 03/ ato2015-2018/2018/lei/L13709.htm. Acesso em: 18 set. 2021.

Ministério da Justiça. Como proteger seus dados pessoais: Disponível em: https://www.gov.br/mj/pt-br/assuntos/noticias/ministerio-da-justica-e-segurancapublica-e-anpd-lancam-guia-de-protecao-de-dados-do-consumidor/guia-doconsumidor v5-5.pdf. Acesso em: 18 set.2021.

Superior Tribunal de Justiça - STJ, Recurso Especial o 1.758.799/MG. Rel. Min. Nancy Andrighi. Brasília, DF, 12 de novembro de 2019. Diário de Justiça Eletrônico. Brasília, 19 nov. 2019. Disponível em https://processo.sti.jus.br/processo/pesquisa/?src=1.1.3\&aplicacao=processos.ea\&tip oPesquisa=tipoPesquisaGenerica\&num registro $=201700065219$. Acesso em: 19 set. 2021.

Supremo Tribunal Federal - STF. ADI no 6387. Relator: Min. Rosa Weber. Brasília, DF, 07 de maio de 2020. Diário de Justiça Eletrônico. Disponível em https://portal.stf.jus.br/processos/detalhe.asp?incidente=5895165. Acesso em: 18 set. 2021

DINIZ, Maria Helena. Responsabilidade civil. 17. ed. São Paulo: Saraiva, 2003.

DONEDA, Danilo. A proteção de dados pessoais como um direito fundamental. In: Espaço Jurídico, Joaçaba, v. 12, n. 2, pp. 91-10, jul./dez. 2011. Disponível em: https://portalperiodicos.unoesc.edu.br/espacojuridico/article/view/1315. Acesso em: 15 set.2021. 
MAYER-SCÖNBERGER. General development of data protection in Europe. In: AGRE, Phillip; ROTENBERG, Marc (Org.). Technology and privacy: The new landscape. Cambridge: MIT Press, 1997.

PESSOA, João Pedro Seefeldt. O Efeito Orwell na sociedade em rede: cibe segurança, regime global de vigilância social e direito à privacidade no século XXI. Porto Alegre: Editora Fi, 2020. Disponível em: https://www.editorafi.org/073orwell. Acesso em: 15 set. 2021.

RIO GRANDE DO SUL. Primeira Turma Recursal da Fazenda Pública. Recurso Cível no 71009738089. Porto Alegre, RS, 24 de agosto de 2021. Diário de Justiça eletrônico (DJe). Porto Alegre. Disponível em: https://www.tjrs.jus.br/site php/consulta/consulta processo.php?nome comarca=Tur mas\%20Recursais\&versao $=$ \&versao fonetica $=1 \&$ tipo $=1 \& \mathrm{id}$ comarca $=700$ \&num pro cesso mask $=\&$ num processo $=71009738089 \&$ codEmenta $=7706337 \&$ tem IntTeor $=$ tru e. Acesso em: 15 set. 2021.

SECRETARIA-GERAL ÍBERO-AMERICANA. XIII Cimeira Ibero-Americana de Chefes de Estado e de Governo. Declaração de Santa Cruz de La Sierra de 14 e 15 de novembro de 2003. Disponível em: https://www.segib.org/wpcontent/uploads/DECLARASAO-STA-CRUZ-SIERRA.pdf. Acesso em: 15 set. 2021.

STIEFELMANN, Roger Leal. Memória Jurisprudencial: Ministro Orozimbo Nonato. Brasília. Supremo Tribunal Federal, 2007. Disponível em: http://www.stf.jus.br/arquivo/cms/publicacaoPublicacaolnstitucionalMemoriaJurisprud lanexo/OrozimboNonato.pdf. Acesso em: 15 set 2021. 